\title{
Enhancing Organizational Citizenship Behavior (OCB) through Transformational Leadership, Interpersonal Communication, and Work Motivation
}

\author{
Syamsudin*, Billy Tunas, Rita Retnowati \\ Post Graduate Program, Pakuan University Bogor, Indonesia.
}

*Corresponding Author: Syamsudin, Post Graduate Program, Pakuan University Bogor, Indonesia.

\begin{abstract}
The purpose of this study to determine the problems of poor Organizational Citizenship Behavior $(O C B)$ of Teachers. The independent variables in this study are Transformational leadership, Interpersonal Communication, and Work Motivation. The selected sample amounted to 216 teachers on Islamic Junior High School in East Jakarta. This study used Mixed Method with Sequential Explanatory, started with a quantitative method then followed with a qualitative method to get a more profound result and more comprehensive result. Further, Scientific Identification Theory of Operation Research in Education Management (SITOREM) is used to rank the hierarchy of improvement.
\end{abstract}

The results of this research indicate a significant positive relationship between: (1) Transformational Leadership with Organizational Citizenship Behavior $(O C B)$, with correlation coefficient ry ${ }_{1}=0.518$ and coefficient of determination $r_{y l}^{2}=0.268$ (2) Interpersonal Communication with Organizational Citizenship Behavior $(O C B)$ with coefficient correlation $r y_{2}=0.639$ and coefficient determination $r_{y 2}^{2}=0.408(3)$ Work Motivation with Organizational Citizenship Behavior $(O C B)$ with coefficient correlation ry $y_{3}=0,356$ and coefficient of determination $r_{y 3}^{2}=0.126$ (4) Transformational Leadership, Interpersonal Communication and Work Motivation together with Organizational Citizenship Behavior $($ OCB), regression equation $=32.07+$ $0.153 X_{1}+0.425 X_{2}+0.182 X_{3}$ with correlation coefficient ry ${ }_{123}=0.704$, and the coefficient of determination $r^{2} y_{123}=0.496$ indicating that the percentage of contribution of independent variables collectively to the dependent variable is equal to $49.6 \%$, while the rest of $50.4 \%$ is influenced by other variables not included in this research model. The results of this quantitative study are also reinforced by qualitative research.

Keywords: Transformational Leadership, Interpersonal Communication, Work Motivation, Organizational Citizenship Behavior (OCB), Teachers.

\section{INTRODUCTION}

In Law number 20 of 2003 concerning the Indonesian National Education System article 3 stipulates that the goal of national education is to develop the potential of students to become human beings who believe and fear the Almighty God, noble, healthy, knowledgeable, capable, creative, independent, and become a democratic and responsible citizen. The act mandates to empower all Indonesian citizens to develop into quality human beings so that they are able and proactively to respond to the challenges of an ever-changing era. The human qualities needed by the Indonesian people in the future will be able to face increasingly fierce competition. Thus, the quality of Indonesian humans is produced through the implementation of quality education, where teachers have a very strategic function, role, and position.

Robins and Judge (2015) state that a dynamic organization requires employees who are willing to contribute and do work that is not part of the employee's formal job requirements, and also contribute to the psychological and social environment of the workplace. Given the enormous function of teachers in the world of education, in this case, teachers are required to have behavior in working beyond the demands of the workload that is the duty of the teacher, namely in the form of organizational citizenship behavior (OCB). In school, leaders (principals) have an essential role in directing, motivating and evaluating the work of teachers with optimal communication to adhere to organizational goals. A leader not only uses his power in carrying out his duties but also is expected to have the ability to understand the people he leads when finding obstacles in work and sensitive in dealing with various situations and conditions of his organization so that leaders can quickly make 
decisions for change in a more well direction. The attitude of a good leader, such as charisma, has an ideal influence, becomes a motivation and inspiration, provides a stimulus and positive values, has empathy, has excellent communication skills, a polite personality and can make a better chance for his organization is characteristic of transformational leadership that will be used as a reference and example for employees in their work environment (Colquitt, Lepine and J.Wesson 2015). This characteristic will foster positive OCB for the organization.

Another factor that has to do with OCB is interpersonal communication, namely the communication skills of individuals in supporting the daily work processes of employees. Cooperation and involvement between individuals who are one another will be stronger if communication runs smoothly so that the impact of creating comfort in work, making sense of brotherhood solidarity increasingly tight in the organization (Kinicki \& William, 2008). Another factor associated with OCB is work motivation. A person's mental state is one of the elements that make a teacher still has a work motivation that is consistent and has a great soul to continue to make the best contribution possible. This work motivation will affect someone in behaving. Motivation is a set of dynamic forces and an urge to desire activities and strengths that determine their goals, intensity, and endurance to achieve achievements in the scope of work and duties (Colquitt, Lepine, and J. Wesson, 2015). This way, teacher motivation is also one of the factors that are thought to influence OCB. Based on the background described, this study will analyze OCB teachers in terms of transformational leadership, interpersonal communication, and work motivation.

\section{LITERATURE REVIEW}

Colquitt, Lepine and J. Wisson (2015), argued that OCB is voluntary individual voluntary behavior that is not affected by a reward system that contributes to the organization. In this case, OCB is categorized into two main categories:

\subsection{Interpersonal Citizenship Behavior}

Which is behavior that benefits colleagues and colleagues, by involving themselves to help coworkers who have heavy workloads, help in personal matters, support and develop the ability of coworkers, and provide assistance to new employees.

Interpersonal Citizenship Behavior includes:

- Helping: Which is to help colleagues who have a heavy workload, involve themselves in alleviating the workload in the organization as well as the personal problems of other employees, as well as providing assistance to new employees.

- Courtesy: Which is the behavior of giving relevant information to colleagues who need and maintain good relations, courtesy and respect with coworkers to avoid interpersonal problems

- Sportsmanship: Namely the behavior of maintaining a right attitude with coworkers, tolerance for less ideal conditions in the organization without complaining and raising objections.

\subsection{Organizational Citizenship Behavior}

Namely behavior that benefits the organization by providing support and defense, working better, and being loyal to the organization. Such behavior includes:

- Voice: Which is actively involved in giving opinions and constructive suggestions for change in a better direction

- Civic Virtue: Which is active behavior in participating in organizations more than usual, actively attending meetings, actively following information related to developments and things that affect the condition of the organization.

- Boosterism: Which is the behavior of promoting the organization positively, always saying good things about the organization, and keeping organizational secret.

From the various theories, it is synthesized that OCB is a certain individual behavior that is shown by someone in an organization that is voluntary, informal, and exceeds the formal expectations of the organization to contribute to the achievement of organizational goals. The indicators are: 1) altruism, 2) courtesy, 3) sportsmanship, 4) Voice, 5) civic virtue, 6) boosterism. 
Transformational leadership involves inspiring followers to commit to a shared vision that provides meaning to their work while also serving as a role model who helps followers develop their potential and view problems from new perspectives. Transformational leaders heighten followers awareness of the importance of specific outcomes while increasing their confidence that those outcomes can be achieved. What gets transformed is the way followers view their work, causing them to focus on the collective good more than just their short-term self-interests and to perform beyond expectations as a result (Colquitt, Lepine dan Wesson, 2015). Transformational leadership is leadership that engages followers and inspires them to commit to a shared vision that gives meaning to their work; leaders also act as role models that help followers develop their potential and see problems from a new perspective. Transformational leaders increase followers' awareness of the importance of certain results while increasing their confidence that these results can be achieved. What is transformed is how followers see their work, making them focus on the collective good more than their own shortterm personal interests and to make further expectations as a result. The dimensions of transformational leadership are 1) idealized influence (2) inspirational motivation (3) intellectual stimulation and 4) individualized consideration.

Luthans (2006) suggests that interpersonal communication represents the background between electronic media and information technology on the one last and nonverbal communication on the other, at the heart of the study of organizational behavior is interpersonal communication".

Interpersonal communication is an intermediary between electronic media and communication technology, on the one hand, last communication and communication between humans. The factors that influence are 1) information delivery 2) information reception, and 3) feedback. Furthermore, Kinicki \& William (2008) concluded that interpersonal communication is the ability of individuals in an organization in terms of skilled communication well to help groups, make decisions that are more innovative and promoted more often than people with less developed abilities. The indicators are: a) firm, push hard without attacking others, b) aggressive, take advantage of others, expressive and improve themselves, c) not assertive, encourage others to take advantage of others, inhibit, and deny themselves. Dressler (2008) concluded that effective interpersonal communication depends on the sender's ability to get the message across and the recipient's performance as an active listener. The indicators put forward are: a) empathizing, someone's ability to understand, sensitive to the feelings, thoughts, and situations of others, b) repeat messages: repeat important points several times, c) use time effectively: messages that compete with other messages, d) noise, so that the recipient is not bothered by anything else, and is descriptive, focusing on the problem is not the person.

Based on the description of the theory above, it can be synthesized that interpersonal communication is the behavior of delivering messages and exchanging information between individuals, is direct and face-to-face, and produces feedback so that the message can be understood. The indicators are: 1) delivery of information, 2) sense of empathy, 3) feedback on the information delivered, 4) receipt of information, 5) use of time effectively, 6) same perception of information delivered.

According to Frederick Herzberg (in Robbins, 2015), there is a known theory of two factors, namely Motivational Factors and Hygiene or maintenance factors. Motivational factors are impulses for achievement that are intrinsic, which means sourced from within a person, while Hygiene Factors or maintenance are extrinsic factors which mean sourced from outside a person. Herzberg views that job satisfaction stems from the existence of an intrinsic motivator and that work dissatisfaction comes from the absence of extrinsic factors. Extrinsic factors (work context) include: (1) Salary: i.e. aspects related to salary, salary increases and employee expectations on salary from their performance, (2) working conditions: This aspect relates to workplace conditions, work environment, work facilities obtained by employees, (3) Job security: Aspects relating to security felt by employees while working, (4) Company procedures: This aspect relates to the organization and management of a regular company, regulations and company administration, (5) Quality supervision: This aspect relates to the way the boss provides guidance to his subordinates, (6) The quality of interpersonal relationships between colleagues, superiors, and subordinates: This aspect relates to the way employees interact with people in the workplace. The existence of these conditions for employee satisfaction does not always motivate them. However, their absence causes dissatisfaction for employees because they need to maintain at least a level of "no satisfaction," an extrinsic condition called dissatisfaction or hygiene factors. Intrinsic factors include: (1) Achievement of achievement: This aspect relates to the effort 
made by someone to achieve optimal work performance, (2) Recognition: This aspect relates to recognition or appreciation given to employees for their performance, (3) Responsibilities: This aspect includes matters relating to responsibility and authority to employees, (4) Progress: This aspect relates to the opportunity of employees to be able to progress in their work, (5) Job itself: This aspect relates to the challenges perceived by employees from their jobs, (6) Possibility of developing: This aspect relates to opportunities that employees will get to improve their careers and future. The absence of these conditions does not mean proving that conditions are very dissatisfied. However, if there is, it will form a strong motivation that produces good work performance. Therefore, extrinsic factors are referred to as satisfaction or motivators.

Tumipseed (2012) said that workers who are externally motivated are less interested in the work itself, but rather towards meeting basic human drives and basic (especially low order) needs. Therefore, they tend to put a little effort into job success. They only achieve instrumental goals, without getting intrinsic satisfaction or happiness from doing their work. Also, they appear to be more likely to be depressed and tormented by everything they see as work-related.

Based on the description above, it can be synthesized that the notion of work motivation is an impulse and desire that is in a person to carry out his work tasks well for the purpose to be achieved. The indicators of work motivation, in the form of a,) Intrinsic motivation, consist of (1) achievement, (2) recognition, (3) responsibility, (4) progress, (5) job itself, (6) possibility of developing, b ) extrinsic motivation, in the form of (1) salary, (2) working conditions, (3) job security, (4) company procedures, (5) quality of supervision, (6) quality of interpersonal relationships among fellow coworkers, superiors, and subordinates.

Based on the above description, the following hypothesis is formulated:

1. Transformational Leadership is positively related to Organizational Citizenship Behavior.

2. Interpersonal Communication is positively related to Organizational Citizenship Behavior.

3. Work motivation is positively related to Organizational Citizenship Behavior.

4. Transformational leadership, interpersonal communication, and working motivation altogether are positively related to Organizational Citizenship Behavior.

\section{MethodologY}

This study applies a Sequential Explanatory Design Mixed Method where the quantitative study is ahead of a qualitative study to examine the relationship between variables tested in the study using three independent variables through data obtained from questionnaires. The independent variable is Transformational Leadership $\left(\mathrm{X}_{1}\right)$, Interpersonal Communication $\left(\mathrm{X}_{2}\right)$, and Work Motivation $\left(\mathrm{X}_{3}\right)$, while the dependent variable is Organizational Citizenship Behavior (Y).

The relationship among variables in the study described in Fig.1 below:

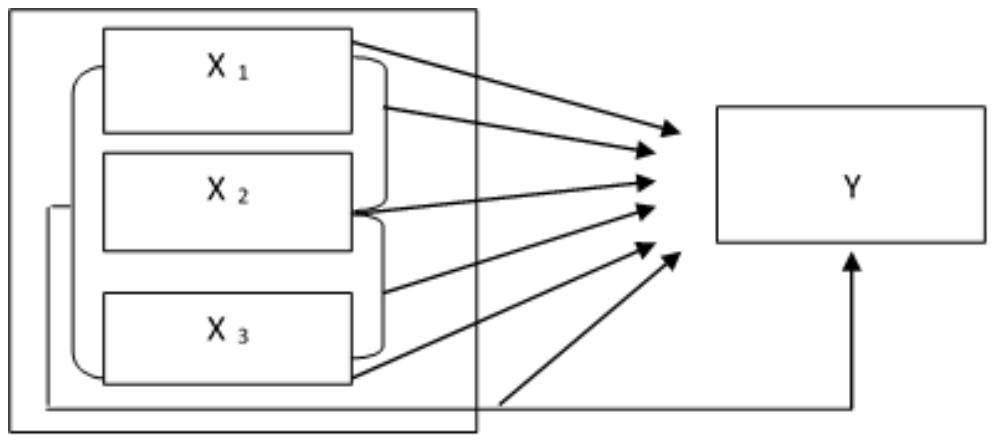

Figure1. Theoretical framework

Where,

$\mathrm{Y}=$ Organizational Citizenship Behavior

$\mathrm{X}_{1}=$ Transformational Leadership

$\mathrm{X}_{2}=$ Interpersonal Communication

$\mathrm{X}_{3}=$ Work Motivation 
The population of this study is 476 Islamic Junior High school teachers in East Jakarta, Indonesia. Calculated with Taro Yamane formula, the sample obtained was 216 teachers. Hypothesis testing is conducted by using regression analysis to determine the influence of one or more independent variables on the dependent variable. The linearity assumption is prerequisites to proceeding to test further. Hypothesis testing is performed at a significance level of 0.05 .

Qualitative study for confirmation was performed at three schools representing upper, middle and lower OCB through observation and interview to the critical informant as well as conducting focus group discussion with school principal and teachers. Finally, the Scientific Identification Theory of Operation Research in Education Management (SITOREM) is applied to rank the areas maintained and improved.

\section{RESULT AND DISCUSSION}

The teachers of listed organizations were asked to participate in the survey by responding to their opinions for four different measures in, leadership, interpersonal communication, work motivation, and OCB. The linearity test is performed with F-test. Data is linear as the value of each variable is above the critical value for F-test.

\subsection{Transformational Leadership and Organizational Citizenship Behavior}

In order to test whether data from transformational leadership and organizational citizenship behavior are linear, F-test has been conducted. Since the F value as shown in table 1 is higher than the critical value of $\mathrm{F}$ table, we can proceed to test the alternate hypothesis if transformational leadership is positively related to organizational citizenship behavior in Islamic Junior High school teachers located in East Jakarta, Indonesia. The strength of the association of transformational leadership $\left(\mathrm{X}_{1}\right)$ to organizational citizenship behavior $(Y)$ is observable from coefficient correlation $\left(r_{x 1}\right)=0.518$.

Table1. Linearity test and coefficient of correlation of transformational leadership $\left(X_{I}\right)$ to organizational citizenship behavior $(Y)$

\begin{tabular}{|c|c|c|c|l|l|}
\hline Observation & $\mathbf{R}$ & $\mathbf{R}^{2}$ & $\mathbf{F}_{\text {-test }}$ & $\mathbf{F}_{\text {-tabel }} \alpha$ & Conclusion \\
\hline $\mathbf{n}$ & $\mathbf{R}_{\mathbf{x} 1}$ & $\mathrm{r}_{\mathbf{x} 1}^{2}$ & $\mathbf{F}_{\mathbf{x} 1}$ & 0.05 & \\
\cline { 1 - 4 } & 0.518 & 0.268 & 5.873 & 2.073 & Linear/Significant \\
\hline
\end{tabular}

$\mathrm{F}_{\text {test }}=5.873$ is above critical value where $\mathrm{F}_{\text {-table }}$ for $(\alpha=0.05)$ is 2.073 indicating that the data is linear and eligible for the next process. The coefficient of correlation $\left(r_{x 1}\right)=0.518$ indicates a medium positive relationship between transformational leadership and organizational citizenship behavior. Coefficient of determination $\left(\mathrm{r}_{\mathrm{x}}^{2} 1\right)=0.268$ indicates that contribution of transformational leadership to organizational citizenship behavior is $26.8 \%$. This implies that when implementing organizational citizenship behavior on teachers is that all the school principals must display a good example. The result of this study is in line with previous research (Al-Sharafi, \& Rajiani, 2013).

\subsection{Interpersonal Communication and Organizational Citizenship Behavior}

In order to test whether data from interpersonal communication and organizational citizenship behavior are linear, F-test has been conducted. Since the F value as shown in table 2 is higher than the critical value of $\mathrm{F}$ table, we can proceed to test the alternate hypothesis if interpersonal communication is positively related to organizational citizenship behavior in Islamic Junior High school teachers located in East Jakarta, Indonesia. The strength of the association of interpersonal communication $\left(\mathrm{X}_{2}\right)$ to organizational citizenship behavior $(\mathrm{Y})$ is observable from coefficient correlation $\left(\mathrm{r}_{\mathrm{x} 2}\right)=0.639$.

Table2. Linearity test and coefficient of correlation of Interpersonal Communication $\left(X_{2}\right)$ to Organizational Citizenship Behavior $(Y)$

\begin{tabular}{|c|c|c|c|l|l|}
\hline Observation & \multicolumn{1}{|c|}{$\mathbf{R}$} & $\mathbf{R}^{2}$ & $\mathbf{F}_{\text {-test }}$ & \multicolumn{1}{|c|}{$\mathbf{F}_{\text {-table }} \alpha$} & \multirow{2}{*}{ Conclusion } \\
\cline { 1 - 5 } $\mathbf{n}$ & $\mathbf{R}_{\mathbf{x} 2}$ & $\mathbf{r}^{2}{ }_{\mathbf{x} 2}$ & $\mathbf{F}_{\mathbf{x} 2}$ & 0.05 & \\
\cline { 1 - 5 } & 0.639 & 0.408 & 5.873 & 3.730 & Linear/Significant \\
\hline
\end{tabular}

The table shows that $F_{\text {test }}=5.873$ is above critical value where $F_{\text {-table }}$ for $(\alpha=0.05)$ is 3.730 indicating that the data is linear and eligible for the next process. The coefficient of correlation $\left(r_{x 2}\right)=0.639$ indicates a strong positive relationship between interpersonal communication and organizational 
citizenship behavior. The coefficient of determination $\left(\mathrm{r}^{2}{ }_{\mathrm{x}} 2\right)=0.408$ indicates that the contribution of interpersonal communication to organizational citizenship behavior $40.8 \%$ while the rest $59.2 \%$ is determined by other factors not included in the model. The result of this study is in line with previous research (Herfina et al., 2015).

\subsection{Work Motivation and Organizational Citizenship Behavior}

Similar to the previous model, to identify if data from working motivation and teachers' innovativeness are linear, F-test has been conducted. The higher $\mathrm{F}$ value as shown in table 3 compared to the critical value of $\mathrm{F}$ table indicates the appropriateness of the model to test the alternate hypothesis if working motivation is positively related to organizational citizenship behavior in Islamic Junior High school teachers located in East Jakarta, Indonesia. The strength of the association of work motivation $\left(\mathrm{X}_{3}\right)$ to organizational citizenship behavior $(\mathrm{Y})$ is observable from coefficient correlation $\left(\mathrm{r}_{\mathrm{x} 3}\right)=0.356$.

Table3. Linearity test and coefficient of correlation of work motivation $\left(X_{3}\right)$ to organizational citizenship behavior $(Y)$

\begin{tabular}{|c|c|c|c|l|l|}
\hline Observation & \multicolumn{1}{|c|}{$\mathbf{R}$} & $\mathbf{R}^{2}$ & $\mathbf{F}_{\text {-test }}$ & \multicolumn{1}{|c|}{$\mathbf{F}_{\text {-table }} \alpha$} & \multirow{2}{*}{ Conclusion } \\
\hline $\mathbf{n}$ & $\mathbf{R}_{\mathbf{x} 3}$ & $\mathrm{r}_{\mathbf{x} 3}^{2}$ & $\mathbf{F}_{\mathbf{x} 3}$ & 0.05 & \\
\cline { 1 - 4 } & 0.356 & 0.126 & 5.873 & 3.753 & Linear/Significant \\
\hline
\end{tabular}

The table shows that $F_{\text {test }}=5.873$ is above critical value where $F_{\text {-table }}$ for $(\alpha=0.05)$ is 3.753 indicating that the data is linear and eligible for the next process. The coefficient of correlation $=0.356$ indicates a weak positive relationship between work motivation and organizational citizenship behavior. The coefficient of determination $\left(\mathrm{r}^{2}{ }_{\mathrm{x} 3}\right)=0.126$ indicates that the contribution of work motivation to organizational citizenship behavior is $12.6 \%$ while the rest $87.4 \%$ is determined by other factors not included in the model. The result of this study is in line with previous research (Ariyani et al., 2016).

\subsection{Organizational Culture, Transformational Leadership and Working Motivation to Teachers' Innovativeness}

When tested together, the model derives the following equation:

$\hat{\mathrm{Y}}=32.07+0.153 \mathrm{X}_{1}+0.425 \mathrm{X}_{2}+0.182 \mathrm{X}_{3}$

The coefficient correlation produced is 0.704 , and the coefficient of determination is 0.496 .

The results obtained for the coefficient of determination a together amounted to 0.496, which means that $49.6 \% \mathrm{OCB}$ is the result of the work of transformational leadership, interpersonal communication, and work motivation together, while $50.4 \%$ is contributed by other variables that have a relationship with OCB. The findings obtained in this study indicate that if the behavior of a leader can transform the values adopted by his followers to achieve organizational vision and goals, Teacher behavior in delivering messages and information exchange between individuals is direct and face-to-face to produce feedback that can be understood. Also, it displays the strength or energy of work from within the teacher (intrinsic) and from outside the teacher (extrinsic) in generating, maintaining and moving business and work behavior continuously to achieve goals. This will be able to increase voluntary behavior to do jobs exceeding the formal expectations required by the organization which includes positive behavior, patience and willingness to bear the occasional costs, which are not affected by the reward system but contribute to the progress of the organization. Thus it can be seen if the leader has good transformational leadership, the teacher has high interpersonal communication behavior, and the teachers have a good motivation to work together so that it will be able to increase the OCB value of a teacher.

Similarly, based on qualitative research, the results of interviews, observation and documentation analysis in three Islamic Junior High in East Jakarta, it can be seen that there is a tendency for a positive relationship between transformational leadership, interpersonal communication, and work motivation together with OCB. This shows the strengthening of quantitative research results of hypothesis testing which states that there is a functional relationship between transformational leadership, interpersonal communication and work motivation with OCB with significant regression and shows that each increase in transformational leadership scores, interpersonal communication, and 
work motivation will increase OCB. Based on the results of interviews on qualitative studies it can be seen that there are other factors besides transformational leadership, interpersonal communication and work motivation that are considered to be related to OCB, which are an organizational commitment, job satisfaction, and organizational culture.

From the results of the SITOREM analysis (Hardhienata, 2017) it can be seen that the weight and average empirical value of each indicator in the OCB variable is as follows: 1) Civic Virtue: weight $28.15 \%$, average empirical value $4.03,2$ ) Altruism: weight $19.75 \%$; average empirical value $3.64,3$ ) Courtesy: weight $14.47 \%$; average empirical value $4.66,4)$ Boosterism: weight $14.42 \%$; average empirical value $4.65,5)$ Sportsmanship: weight $14.37 \%$; average empirical value of $4.63,6)$ Voice: weighs $8.85 \%$; average empirical value is 3.80 . The weight and average empirical value of transformational leadership variables for each indicator are as follows: 1) Idealized Influence: weight of 36.99\%; average empirical value 3.94, 2) Inspirational Motivation: weight of $23.26 \%$. Average empirical value of $4.25,3$ ) Intellectual Stimulation: weight of $21.73 \%$; average empirical value 3.97, 4) Individualized Consideration: weight of $18.02 \%$; average empirical value 3.84 . The weight and average empirical value of interpersonal communication variables for each indicator are as follows: 1) Perception: weight $23.47 \%$; with empirical mean value $4.33,2$ ) Openness: weight $23.29 \%$; with empirical mean value 4.29, 3) Empathy: weight $14.27 \%$; with empirical mean value $3.68,4$ ) Equality: weight $13.68 \%$; with empirical mean value $4.41,5)$ Supportiveness: weight $(12.97 \%$; with empirical mean value $4.18,6$ ) Positiveness: weight $12.31 \%$; with empirical mean value 3.97 . The weight and average empirical value of the working motivation variables for each indicator are as follows: 1) Responsibility: weight $17.45 \%$; with an empirical average value of $4.29,2)$ Quality of supervision: weight of 10.72; with empirical mean value 4.40,3) Job itself: weight 10.37; with an empirical average value of $4.25,4$ ) Organizational Procedure: weight 10.01; with an empirical average value of $4.10,5)$ Encouragement of Achievement of Progress: weight 9.83; with an empirical average value of $4.03,6)$ Working Conditions: weight 7.40 ; with empirical average values $4.55,7$ ) Quality of Interpersonal Relations: weights 7.16; with empirical mean values 4.41, 8) Work Safety: weight 6.97; with empirical mean values $4.29,9$ ) Evolving possibilities: weight 6.92 ; with an empirical mean value of $4.25,10)$ Salaries and Allowances: weights 5.70; with an empirical average value of $3.51,11$ ) Encouragement Achievement: weight 5.56; with empirical mean value 3.42, 12) Encouragement of gaining recognition: weight 1.92; with an empirical mean value of 2.36 .

\section{CONCLUSiON}

The findings prove that there is a positive and significant relationship between the transformational leadership, interpersonal communication and work motivation on teachers' OCB among teachers working in Islamic Junior High Schools located in East Jakarta, Indonesia. With particular reference to the initial design of the interaction among variables, the results showed that the contribution of transformational leadership is $26.8 \%$, interpersonal communication is $40.8 \%$, and working motivation is $12.6 \%$ indicating the highest individual contribution to the OCB of teachers is interpersonal communication. When combined, the contribution of the three variables of transformational leadership, interpersonal communication, and work motivation achieve $49.6 \%$ indicating the contribution of other variables not included in the model to predict teachers' OCB is $50.4 \%$ indicating this model is of marginal goodness of fit.

Based on interviews in the qualitative study it is revealed other factors than transformational leadership, interpersonal communication, and motivation of teachers associated with teachers' OCB. Those factors are organizational commitment, job satisfaction, and organizational culture.

\section{REFERENCES}

[1] Ariyani, Ida, Siti Haerani, Haris Maupa dan Muh. Idrus Taba (2016), The Influence of Organizational Culture, Work Motivation and Working Climate on the Performance of Nurses through Job Satisfaction, Organizational Commitment and Organizational Citizenship Behavior in the Private Hospitals in Jakarta, Indonesia, Scientific Research Journal (SCIRJ), Volume IV, Issue VII, July 201615 ISSN 2201-2796

[2] Al-Sharafi, H., \& Rajiani, I. (2013). Leadership practices and talent turnover: Study on Yemeni organizations. Business and Management Research, 2(3), 60-67.

[3] Colquitt, J., Lepine, J., Wesson, M.J., (2015), Organizational Behavior, Improving Performance and Commitment in the Workplace. New York: Mc Graw-Hill Companies Inc. 
[4] Dessler, G., (2008), Human Resource Management, Prentice Hall, Rinehart and Winston, New York USA.

[5] Hardhienata, S. The development of scientific identification theory to conduct operation research in education management, IOP Conf. Series: Materials Science and Engineering 166 (2017) 012007 doi:10.1088 / 1757 - 899X / 166 / I / 012007.

[6] Herfina, Thamrin Abdullah dan Bibin Rubini (2015), The Relationship among Transformational Leadership, Work Satisfaction, and Interpersonal Communication to Teachers' Organizational Citizenship Behavior. International Journal of Managerial Studies and Research (IJMSR) Volume 3, Issue 4, April 2015, PP 11-16 ISSN 2349-0330.

[7] Kinicki, A., \& Williams, B.K., (2008), Management; A. Practical introduction, Third Edition.

[8] Luthans, F., (2006), Perilaku Organisasi, Edisi Sepuluh, Penerbit Andi, Yogjakarta.

[9] Robbins, Stephen P., and Judge, Timothy A. (2015), Organizations Behavior, 15th edition. New York: Pearson Education, Inc.

[10] Tumipseed, David L., (2012), Handbook of Organizational Citizenship Behavior: A Review of Good Soldier Activity in Organizations. New York: Nova Science Publishers, Inc

Citation: Syamsudin, Billy Tunas, Rita Retnowati. "Enhancing Organizational Citizenship Behavior (OCB) through Transformational Leadership, Interpersonal Communication, and Work Motivation" International Journal of Managerial Studies and Research (IJMSR), vol 7, no. 4, 2019, pp. 54-61. doi: http://dx.doi.org/ 10.20431/2349-0349.0704008.

Copyright: (C) 2019 Authors. This is an open-access article distributed under the terms of the Creative Commons Attribution License, which permits unrestricted use, distribution, and reproduction in any medium, provided the original author and source are credited. 